\title{
Insight into the Nature of Iron Sulfide Surfaces During the Electrochemical Hydrogen Evolution and $\mathrm{CO}_{2}$ Reduction Reactions
}

\author{
Siti N. A. Zakaria, ${ }^{\dagger \dagger}$ Nathan Hollingsworth, ${ }^{\dagger}$ Husn U. Islam, ${ }^{\dagger}$ Anna Roffey, ${ }^{\dagger}$ David Santos-Carballal, ${ }^{\S}$
} Alberto Roldan, ${ }^{\S}$ Wim Bras, ${ }^{\| \odot}$ Gopinathan Sankar, ${ }^{\dagger}$ Graeme Hogarth, ${ }^{\perp}$ Katherine B. Holt, ${ }^{*}{ }^{\dagger} \odot$ and Nora H. de Leeuw ${ }^{*},, \S^{\circ}$

${ }^{\dagger}$ Department of Chemistry, University College London, 20 Gordon Street, London WC1H 0AJ, U.K.

${ }^{\ddagger}$ Faculty of Science, Universiti Brunei Darussalam, Jln Tungku Link, Gadong BE1410, Brunei

${ }^{\S}$ School of Chemistry, Cardiff University, Main Building, Park Place, Cardiff CF10 3AT, U.K.

"European Synchrotron Radiation Facility, BP220, Grenoble F38043, France

${ }^{\perp}$ Department of Chemistry, Kings College London, Britannia House, 7 Trinity Street, London SE1 1DB, U.K.

\section{Supporting Information}

ABSTRACT: Greigite and other iron sulfides are potential, cheap, $\mathrm{H}_{2} \mathrm{O}$ earth-abundant electrocatalysts for the hydrogen evolution reaction (HER), yet little is known about the underlying surface chemistry. Structural and chemical changes to a greigite $\left(\mathrm{Fe}_{3} \mathrm{~S}_{4}\right)$-modified electrode were determined at $-0.6 \mathrm{~V}$ versus standard hydrogen electrode ( $\mathrm{SHE})$ at $\mathrm{pH} 7$, under conditions of the HER. In situ X-ray absorption spectroscopy was employed at the Fe K-edge to show that iron-sulfur linkages were replaced by iron-oxygen units under these conditions. The resulting material was determined as $60 \%$ greigite and $40 \%$ iron hydroxide (goethite) with a proposed core-shell structure. A large increase in $\mathrm{pH}$ at the electrode surface (to $\mathrm{pH} 12$ ) is caused by the generation of $\mathrm{OH}^{-}$as a product of the HER. Under these conditions, iron sulfide materials are thermodynamically unstable with respect to the hydroxide. In situ infrared spectroscopy of the solution near the electrode interface confirmed changes in the phosphate ion speciation consistent with a change in $\mathrm{pH}$ from 7 to 12 when $-0.6 \mathrm{~V}$ versus SHE is applied. Saturation of the solution with $\mathrm{CO}_{2}$ resulted in the inhibition of the hydroxide formation, potentially due to surface adsorption of $\mathrm{HCO}_{3}{ }^{-}$. This study shows that the true nature of the greigite electrode under conditions of the HER is a core-shell greigitehydroxide material and emphasizes the importance of in situ investigation of the catalyst under operation to develop true and accurate mechanistic models.

KEYWORDS: greigite, iron sulfide, hydrogen evolution reaction, $\mathrm{CO}_{2}$ reduction, electrocatalyst

\section{INTRODUCTION}

Metal sulfides find extensive use as electrode materials in $\mathrm{Li}$ ion batteries and as electrocatalysts. ${ }^{1-3}$ In aqueous media, sulfides of molybdenum, ${ }^{4,5}$ nickel, $^{6}$ and cobalt ${ }^{7}$ among others have been shown to catalyze the hydrogen evolution reaction (HER) and thus are considered as nonprecious metal alternatives to platinum for electrocatalytic hydrogen generation from water. ${ }^{2,3}$ The cheap and earth-abundant iron sulfide materials such as pyrite ${ }^{8-11}\left(\mathrm{FeS}_{2}\right)$, pyrrhotite ${ }^{12}$ $\left(\mathrm{Fe}_{1-x} \mathrm{~S}\right)$, and greigite $\left(\mathrm{Fe}_{3} \mathrm{~S}_{4}\right)^{13}$ have also been demonstrated as stable electrodes for the HER. For iron sulfides, depending on factors such as sulfide phase, morphology, solution composition, and $\mathrm{pH}$, water reduction is reported to take place at potentials negative of $-0.1 \mathrm{~V}$ versus standard hydrogen electrode (SHE). Good material stability is reported in most cases, as evaluated by constant current density measurements recorded over many hours and reproducibility with respect to repeated use. However, although ex situ characterization of such electrodes has been carried out using
X-ray diffraction (XRD) and Raman and X-ray photoelectron spectroscopy, in situ studies to determine the nature of the catalyst surface under operating conditions are still lacking. In some studies, the iron sulfide material has been re-examined after use with scanning electron microscopy or XRD to determine if structural or chemical changes have taken place under catalytic conditions. However, these techniques would not necessarily reveal the presence of amorphous materials or changes confined to the surface of the catalyst.

It is important to consider the stability of iron sulfides at the negative applied potentials required for the HER, as these materials have a complex redox chemistry. ${ }^{14-20}$ Inspection of the $\mathrm{pH}$-potential (Pourbaix) diagrams for iron sulfides ${ }^{14,21}$ shows that at $\mathrm{pH} 7$ the sulfide is no longer thermodynamically stable at potentials more negative than ca. $-0.4 \mathrm{~V}$ (depending

Received: May 24, 2018

Accepted: July 20, 2018

Published: July 20, 2018 
on the sulfide) and is expected to reduce to $\mathrm{Fe}^{0}$. Thus, it is predicted that under some experimental conditions reported for HER catalysis, the thermodynamically stable form of the iron sulfide electrode is metallic iron. In addition, at neutral $\mathrm{pH}$, the HER reaction proceeds as shown in eq 1

$$
2 \mathrm{H}_{2} \mathrm{O}+2 \mathrm{e}^{-} \rightarrow \mathrm{H}_{2}+2 \mathrm{OH}^{-}
$$

Hence, because of the generation of $\mathrm{OH}^{-}$during the HER, the local $\mathrm{pH}$ at the electrode interface may rise substantially above 7 if buffering is not effective. ${ }^{22}$ As iron sulfide speciation is both $\mathrm{pH}$ - and potential-dependent, it is important to determine the stability of the iron sulfide electrode under such local $\mathrm{pH}$ changes. Indeed, for studies carried out under basic conditions, the transformation of iron sulfide to hydroxide and oxyhydroxide could proceed even in the absence of an applied potential. Given that theoretical models often assume a pristine "as-prepared" catalyst surface, ${ }^{10}$ to truly achieve mechanistic understanding and further improve catalyst performance, experimental determination of the catalyst surface chemistry during the reaction is required.

In this contribution, we describe the use of in situ X-ray absorption spectroscopy (XAS) to monitor the oxidation state and coordination environment of the iron centers in greigite as a function of applied electrode potential at $\mathrm{pH}$ 7. Greigite is an especially interesting case; as being a metastable sulfide, only limited information is available about its stability in the potential and $\mathrm{pH}$ ranges of the HER. In addition, iron is present in both +2 and +3 oxidation states, meaning that the reduction of greigite to $\mathrm{FeS}$ (eq 2) is also possible in the potential range of interest

$$
\mathrm{Fe}_{3} \mathrm{~S}_{4}+2 \mathrm{H}_{2} \mathrm{O}+2 \mathrm{e}^{-} \rightarrow 3 \mathrm{FeS}+\mathrm{H}_{2} \mathrm{~S}+2 \mathrm{OH}^{-}
$$

Figure 1 shows an adapted Pourbaix diagram for greigite over the cathodic potential and $\mathrm{pH}$ ranges of interest. This

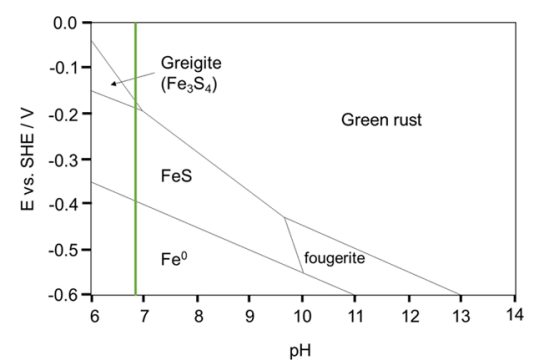

Figure 1. Pourbaix diagram for greigite $\left(\mathrm{Fe}_{3} \mathrm{~S}_{4}\right)$ over the $\mathrm{pH}$ and potential range of interest in this study. Figure is adapted from ref 14 , where $[\mathrm{Fe}]_{T}=10^{-3} \mathrm{~mol} \mathrm{dm}^{-3} ;[\mathrm{S}(-\mathrm{II})]=10^{-3} \mathrm{~mol} \mathrm{dm}{ }^{-3}$; and $T=$ $298 \mathrm{~K}, p=1$ bar. The green line indicates the potential sweep range of $\mathrm{CV}$ in Figure 4 at $\mathrm{pH} 6.8$.

figure has been prepared using references where the reported stability range of greigite does not extend above $\mathrm{pH} 7,{ }^{14,21}$ although it should be noted that Pourbaix diagrams have been calculated that extend the stability range of greigite to higher $\mathrm{pH}$ when the S-to-Fe ratio is higher. ${ }^{23}$ From Figure 1, it is clear that the reduction of greigite to $\mathrm{FeS}$ and then $\mathrm{Fe}^{0}$ is predicted as the applied potential is swept more negative. However, in this work, we show that the XAS spectral changes observed at potentials negative of $-0.6 \mathrm{~V}$ do not indicate reduction of greigite to $\mathrm{FeS}$, but the spectral changes are instead consistent with replacement of sulfur coordination with oxygen. In situ infrared (IR) spectroscopy is employed to show that at negative applied potentials, the $\mathrm{pH}$ at the electrode surface increases from 7 to ca. 12. We propose that under the conditions of the HER, greigite converts to iron hydroxides, as predicted by the Pourbaix diagram (Figure 1), where fougerite $\left(\mathrm{Fe}(\mathrm{II})_{2} \mathrm{Fe}(\mathrm{III})(\mathrm{OH})_{7}\right)$ and green rust (amorphous mixed $\mathrm{Fe}(\mathrm{II}) / \mathrm{Fe}$ (III) hydroxides) are the indicated stable phases at $\mathrm{pH}$ 12. In addition, given that greigite ${ }^{24}$ and other iron sulfides $^{25-27}$ have been shown to act as electrocatalysts for the reduction of $\mathrm{CO}_{2}$, we have repeated these studies in a $\mathrm{CO}_{2}$ saturated solution. $\mathrm{CO}_{2}$ reduction competes with the HER at these electrodes, as potentials more negative than $-0.6 \mathrm{~V}$ versus SHE are required for appreciable conversion of $\mathrm{CO}_{2}$. Repetition of the in situ XAS experiments in the $\mathrm{CO}_{2}$-saturated solution shows that dissolved $\mathrm{CO}_{2}$ inhibits the transformation of greigite to hydroxide. Calculated binding energies suggest that the adsorbed $\mathrm{HCO}_{3}{ }^{-}$species may protect the surface by inhibiting the HER.

\section{METHODOLOGY}

Greigite was synthesized as described previously ${ }^{24}$ (Supporting Information SI1) by solvothermal decomposition of iron dithiocarbamate complexes in oleylamine (Z-octadec-9-enylamine), which acts both as a solvent and capping agent. The resulting amine-capped nanoplatelets were of average dimensions $100 \times 70 \times 20 \mathrm{~nm}$ with the largest surfaces being the $\{100\}$ plane and the $\{111\}$ edges, as determined by high-resolution transmission electron microscopy (HRTEM) (see Figure S1). ${ }^{24}$ For in situ XAS experiments, greigite dispersed in a carbon nanoparticle matrix was used and synthesized in the same way as the pure greigite but with nanocarbon powder present in the reaction vessel.

The greigite nanoparticles were suspended in isopropanol and then drop-coated onto a boron-doped diamond (BDD) working electrode and characterized using cyclic voltammetry (CV). For CV experiments, a standard three-electrode cell was used, composed of the $3 \mathrm{~mm}$ diameter greigite-modified BDD working electrode, a $\mathrm{Pt}$ wire coil counter electrode, and a $\mathrm{Ag} /$ $\mathrm{AgCl}$ (sat. $\mathrm{KCl}$ ) reference electrode. For in situ XAS experiments, an air-tight cell was designed with a Kapton window to allow penetration of X-rays to the electrode surface (Figure 2a). The working electrode was a carbon rod coated with greigite in a carbon matrix and positioned ca. $0.5 \mathrm{~mm}$ from the window. Measurements were taken in fluorescence mode on the Fe K-edge (Supporting Information, SI2), and the X-ray absorption near-edge structure (XANES) was analyzed semiquantitatively with linear combination fitting (LCF) of possible contributions using reference spectra of iron sulfide and hydroxide samples (Supporting Information, SI3). In situ IR spectroscopy was carried out by positioning a greigite-modified BDD electrode directly over the prism of an attenuated total reflectance (ATR) IR spectrometer (Figure $2 \mathrm{~b}$, Supporting Information, SI6). Difference spectroscopy was employed, where first a spectrum of the immersed electrode without a potential applied was measured, which was used as the background for all subsequent spectra. Thus, for the spectra presented in this paper, an IR band showing an increase in absorbance represents a species that increased in concentration when the potential was applied, whereas a negative band represents a species that decreased in concentration. Density functional theory calculations were carried out to predict energies for oxygen incorporation into greigite and binding energies of species at greigite surfaces (Supporting Information, SI7). 


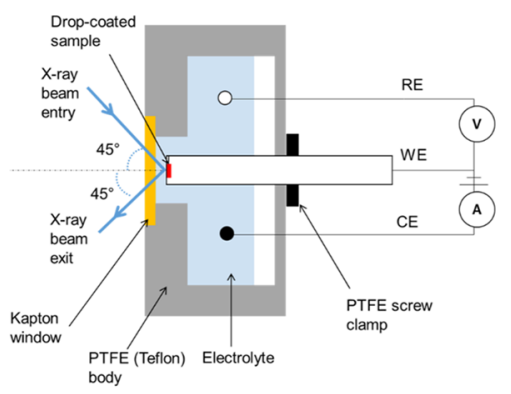

a)

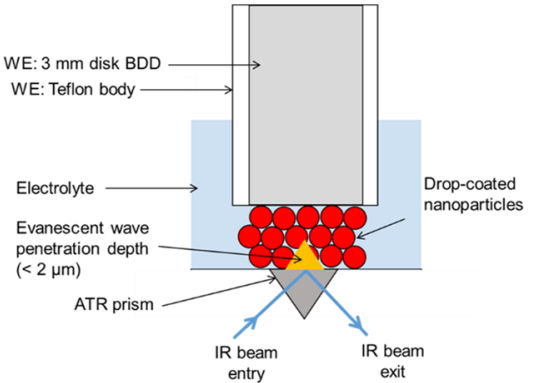

b)

Figure 2. Schemes of (a) in situ XAS electrochemical cell, side view cross section (not to scale). WE = working electrode; CE = counter electrode; $\mathrm{RE}=$ reference electrode; (b) in situ ATR IR experiment (not to scale); BDD = boron-doped diamond.
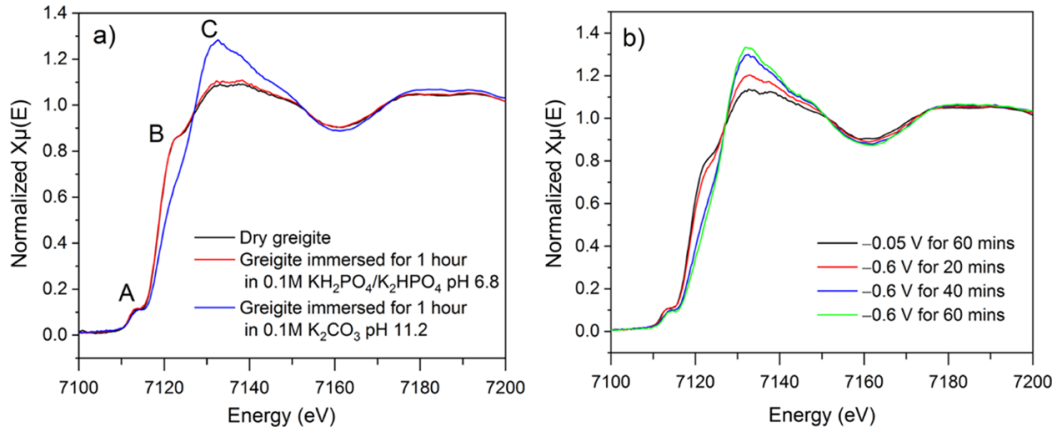

Figure 3. (a) XANES spectra for dry greigite (black); greigite immersed for $1 \mathrm{~h}$ in deoxygenated pH $6.80 .1 \mathrm{M} \mathrm{KH}_{2} \mathrm{PO}_{4} / \mathrm{K}_{2} \mathrm{HPO}_{4}$ solution (red) and $\mathrm{pH} 11.20 .1 \mathrm{M} \mathrm{K}_{2} \mathrm{CO}_{3}$ solution (blue). (b) XANES spectra for the greigite electrode in deoxygenated $\mathrm{pH} 6.80 .1 \mathrm{M} \mathrm{K}_{2} \mathrm{HPO}_{4} / \mathrm{KH}_{2} \mathrm{PO}_{4}$ solution at $-0.05 \mathrm{~V}$ vs SHE for $60 \mathrm{~min}$ (black) and $-0.60 \mathrm{~V}$ vs SHE after $20 \mathrm{~min}$ (red), $40 \mathrm{~min}$ (blue), and $60 \mathrm{~min}$ (green). Labels A-C are described in the text.

\section{RESULTS AND DISCUSSION}

Stability of Greigite in a $\mathrm{pH} 7$ Electrolyte. XANES spectra are shown (Figure 3a) for dry greigite and after immersion for $60 \mathrm{~min}$ in deoxygenated $0.1 \mathrm{M} \mathrm{pH} 6.8$ $\mathrm{KH}_{2} \mathrm{PO}_{4} / \mathrm{K}_{2} \mathrm{HPO}_{4}$ solution with no applied potential. The two are very similar and show a characteristic pre-edge feature $\mathbf{A}$, a shoulder to the edge $\mathbf{B}$, and a white line (edge) intensity C. A represents the forbidden $\mathrm{Fe}$ 1s to $\mathrm{Fe} 3 \mathrm{~d}$ transition, whereas $\mathrm{C}$ shows the first allowed $\mathrm{Fe} 1 \mathrm{~s}$ to $\mathrm{Fe} 4 \mathrm{p}$ transition. ${ }^{28}$ Shoulder $\mathbf{B}$ is an indicator of the coordination between $\mathrm{Fe}$ and $\mathrm{S}$, as it represents the normally forbidden $\mathrm{Fe}$ 1s to $\mathrm{Fe} 4 \mathrm{~s}$ transition. This becomes more allowed and hence more intense, when the $S 3 p$ orbital overlap contributes $p$ character to the $\mathrm{Fe} 4 \mathrm{~s}$ orbital. ${ }^{29,30}$ Shoulder $\mathrm{B}$ is absent or less intense for iron oxides ${ }^{28}$ as the oxygen is harder and hence oxygen $\mathrm{p}$ orbital overlap is less effective. ${ }^{31}$ LCF analysis confirms that the only contribution to the XANES spectrum for both dry and immersed samples is from greigite. The lack of contribution from oxide confirms that the oleylamine capping agent protects greigite from oxidation by air. As immersion in $0.1 \mathrm{M}$ $\mathrm{KH}_{2} \mathrm{PO}_{4} / \mathrm{K}_{2} \mathrm{HPO}_{4}$ does not result in significant spectral changes, this indicates that greigite is stable under neutral conditions even under X-ray irradiation. Moreover, the spectral response is not significantly perturbed by surface coordination of water and phosphate or loss of the capping agent (through dissolution).

Stability of Greigite at Negative Applied Potentials. The greigite-modified electrode was characterized in $0.1 \mathrm{M} \mathrm{pH}$ $6.8 \mathrm{KH}_{2} \mathrm{PO}_{4} / \mathrm{K}_{2} \mathrm{HPO}_{4}$ using $\mathrm{CV}$ (Figure 4). During the first scan, the current is close to zero until $-0.50 \mathrm{~V}$ versus SHE when reduction currents start to flow (R1). On the reverse

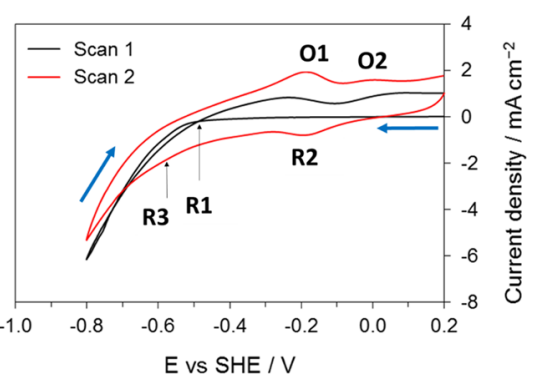

Figure 4. First and second $\mathrm{CV}$ scans of the greigite-modified electrode in deoxygenated $\mathrm{pH}$ 6.8 $0.1 \mathrm{M} \mathrm{K}_{2} \mathrm{HPO}_{4} / \mathrm{KH}_{2} \mathrm{PO}_{4}$ solution. Scan rate $0.01 \mathrm{~V} \mathrm{~s}^{-1}$. Labels $\mathrm{R} 1-3$ and $\mathbf{0 1 - 2}$ are described in the text.

scan, anodic peaks are observed at $-0.20 \mathrm{~V}(\mathrm{O} 1)$ and $0.0 \mathrm{~V}$ (O2). Subsequent scans differ from the first, with additional cathodic peaks present at $-0.20 \mathrm{~V}(\mathrm{R} 2)$ and $-0.55 \mathrm{~V}(\mathrm{R} 3)$. Peaks R2, R3, O1, and $\mathrm{O} 2$ increase in magnitude with repeated cycling; their assignment is considered later. The near-zero current observed between 0 and $-0.5 \mathrm{~V}$ on the first scan suggests the presence of a passivating layer, such as the oleylamine capping agent, on the greigite surface. This inhibits the close approach of electrolyte ions responsible for capacitive currents, as well as slowing the kinetics of the redox processes predicted to occur at these potentials. The Pourbaix diagram ${ }^{14}$ (Figure 1) shows that reduction of greigite to $\mathrm{FeS}$ (eq 2) is feasible at potentials below $-0.20 \mathrm{~V}$ at $\mathrm{pH} 6.8$; however, no reduction currents are observed at this potential. It is possible that R1 may be attributed to this reaction if a passivating layer and slow electron-transfer kinetics result in an overpotential for the process. In addition, negative of $-0.4 \mathrm{~V}$ direct reduction to 
$\mathrm{Fe}^{0}$ also becomes possible and hence $\mathrm{R} 1$ may have contributions from the reaction in eq 3

$$
\mathrm{Fe}_{3} \mathrm{~S}_{4}+8 \mathrm{H}_{2} \mathrm{O}+8 \mathrm{e}^{-} \rightarrow 3 \mathrm{Fe}+4 \mathrm{H}_{2} \mathrm{~S}+8 \mathrm{OH}^{-}
$$

The competing reaction of water reduction (eq 1) could also result in current R1 at this potential, consistent with previous HER studies. ${ }^{10,13,26}$

To determine any changes in the iron oxidation state or coordination environment associated with R1, in situ XANES spectra were recorded at -0.05 and $-0.60 \mathrm{~V}$ versus SHE, with potentials held for $60 \mathrm{~min}$ (Figure $3 \mathrm{~b}$ ). At $-0.05 \mathrm{~V}$, the spectra were identical to those of dry greigite, which is consistent with the lack of redox behavior observed at this potential. The Pourbaix diagram (Figure 1) predicts that greigite should transform to green rust under these conditions, but this is not observed, likely due to slow kinetics or the protection of the greigite surface by the capping agent. At $-0.60 \mathrm{~V}$, the edge shoulder $\mathbf{B}$ was lost over time and the white line intensity $\mathbf{C}$ increased. Loss of $\mathbf{B}$ indicates a decrease in $\mathrm{Fe}-\mathrm{S}$ coordination $^{28}$ and increased white line intensity is characteristic of increased $\mathrm{Fe}-\mathrm{O}$ coordination. ${ }^{32,33}$ Although the shoulder $\mathbf{B}$ is lost, the position of the edge does not shift significantly over time. The edge position is a reflection of the average oxidation state of the iron centers, which remains unchanged throughout the analysis. Hence, there is no evidence in the XANES spectra for the transformation of $\mathrm{Fe}_{3} \mathrm{~S}_{4}$ to $\mathrm{FeS}$, as predicted by eq 2, or further reduction to $\mathrm{Fe}^{0}$. This indicates that although the reactions in eqs 2 and 3 are thermodynamically viable, the kinetics are slow. Spectral changes are instead indicative of replacement of $S$ with $O$ and formation of surface oxide or hydroxide. This interpretation is corroborated by extended X-ray absorption fine structure (EXAFS) analysis, which shows a shortening bond distance in first shell coordination at negative applied potentials, consistent with replacement of longer $\mathrm{Fe}-\mathrm{S}$ bond distances with shorter $\mathrm{Fe}-\mathrm{O}$ distance (Supporting Information, SI4).

One explanation for this observation could be the dominance of the HER at this potential (eq 1) with concomitant generation of $\mathrm{OH}^{-}$, resulting in a $\mathrm{pH}$ increase close to the electrode. According to the Pourbaix diagram, ${ }^{14}$ a $\mathrm{pH}>11$ at $-0.6 \mathrm{~V}$ can result in the transformation of both $\mathrm{Fe}_{3} \mathrm{~S}_{4}$ and its reduction product $\mathrm{FeS}$ into green rusts. These are amorphous mixed $\mathrm{Fe}(\mathrm{II}) / \mathrm{Fe}$ (III) hydroxide species, including fougerite, with stoichiometry depending on $\mathrm{pH}$, potential, trace oxygen, and the presence of other anions. Green rusts are precursors to the iron oxyhydroxide goethite, $\alpha-\mathrm{FeOOH}$. Therefore, a XANES spectrum for goethite was used as a standard "hydroxide" for LCF fitting of the XANES spectra (Supporting Information, SI3). LCF analysis of the XANES spectrum at $-0.60 \mathrm{~V}$ applied for $60 \mathrm{~min}$ (Figure $3 \mathrm{~b}$ ) shows that the final electrode material has a greigite content of $60 \%$ with iron hydroxides (goethite) contributing the remaining $40 \%$. The feasibility of the proposed $\mathrm{pH}$-induced change is supported by comparison of the final XANES spectrum at $-0.60 \mathrm{~V}$ with that recorded for greigite immersed in deoxygenated $\mathrm{pH} 11.2$ electrolyte (Figure $3 \mathrm{a}$ ). In the basic electrolyte, shoulder $\mathbf{B}$ is lost and the white line intensity $\mathbf{C}$ increases, even when no potential is applied and the spectrum matches that shown in green in Figure $3 \mathrm{~b}$. LCF shows the resulting material to have composition similar to greigite held at $-0.60 \mathrm{~V}$ in $\mathrm{pH} 6.8$ electrolyte, that is, $38 \%$ iron hydroxide and $62 \%$ greigite, thus confirming that the observed changes could take place if the $\mathrm{pH}$ at the electrode interface increased to $>11$ when the potential was applied.

Experimental Evidence for Local pH Increase. To show that such a significant $\mathrm{pH}$ change takes place at $-0.60 \mathrm{~V}$, in situ ATR IR difference spectroscopy was used to monitor changes in the relative concentrations of phosphate species at the electrode surface when negative potentials are applied (Figure 5). At $-0.60 \mathrm{~V}$, in Figure $5 \mathrm{~b}$, clear changes in

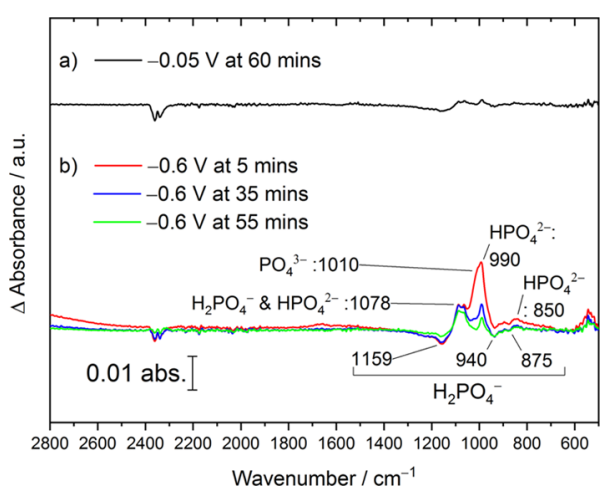

Figure 5. In situ ATR IR difference spectra obtained at the greigitemodified electrode in deoxygenated solution at $\mathrm{pH} \quad 6.8 \quad 0.1 \mathrm{M}$ $\mathrm{K}_{2} \mathrm{HPO}_{4} / \mathrm{KH}_{2} \mathrm{PO}_{4}$ at (a) -0.05 and (b) $-0.60 \mathrm{~V}(5 \mathrm{~min}=$ red; 35 $\min =$ blue; $55 \mathrm{~min}=$ green $)$.

absorbance are seen in the phosphate band region. ${ }^{22,34}$ Increases in absorbance are noted at 850, 990, and 1078 $\mathrm{cm}^{-1}$, corresponding to an increase in $\mathrm{HPO}_{4}{ }^{2-}$ in the IR sampling region close to the electrode. The apparent splitting of the $1078 \mathrm{~cm}^{-1}$ band is due to the concurrent loss in absorbance at $1077 \mathrm{~cm}^{-1}$, which along with negative bands at 1159,940 , and $875 \mathrm{~cm}^{-1}$ indicates a decrease in the interfacial concentration of $\mathrm{H}_{2} \mathrm{PO}_{4}{ }^{-35}$. Initially, a strong positive band is also seen at $1010 \mathrm{~cm}^{-1}$, which decreases in intensity over time and is absent by the final spectrum. The $1010 \mathrm{~cm}^{-1}$ band is assigned to $\mathrm{PO}_{4}{ }^{3-}$ and indicates that application of $-0.60 \mathrm{~V}$ induces deprotonation of the solution phosphate species at the electrode interface. The $\mathrm{p} K_{\mathrm{a}}$ values (not corrected for ionic strength) for eqs 4 and 5 suggest that for the $\mathrm{PO}_{4}{ }^{3-}$ band to emerge in the spectrum, the $\mathrm{pH}$ of the solution at the electrode interface must be close to 12

$$
\begin{aligned}
& \mathrm{H}_{2} \mathrm{PO}_{4}{ }^{-} \rightarrow \mathrm{H}^{+}+\mathrm{HPO}_{4}{ }^{2-} \\
& \mathrm{HPO}_{4}{ }^{2-} \rightarrow \mathrm{H}^{+}+\mathrm{PO}_{4}{ }^{3-}
\end{aligned}
$$

In contrast, at $-0.05 \mathrm{~V}$, only small changes in the spectrum are observed (Figure 5a), indicating little change in interfacial solution speciation at this potential compared to when no potential is applied. The changes that are observed are consistent with small amounts of deprotonation of the $\mathrm{H}_{2} \mathrm{PO}_{4}{ }^{-}$ species in response to the applied potential.

Calculation of $\mathrm{pH}$ Increase at the Electrode. Using the current density, $j$, achieved at $-0.6 \mathrm{~V}$ in Figure 4 , an approximate surface $\mathrm{OH}^{-}$concentration $\left[\mathrm{OH}^{-}\right]_{x=0}$ can be calculated, where $x$ is the perpendicular distance from the surface of the electrode to the bulk of the solution, assuming that all current can be attributed to the water reduction reaction in eq 1 . The magnitude of $j$ can be related to the concentration gradient of $\mathrm{OH}^{-}$at the electrode by eq 6 


$$
j=n F D \frac{\left[\mathrm{OH}^{-}\right]_{x=0}-\left[\mathrm{OH}^{-}\right]_{\mathrm{x}=\delta}}{\delta}
$$

where $D$ is the diffusion coefficient for $\mathrm{OH}^{-}, \delta$ is the diffusion layer thickness, $n$ is the number of electrons transferred per $\mathrm{OH}^{-}$formed (in this case 1), and $\left[\mathrm{OH}^{-}\right]_{\mathrm{x}}=\delta$ is the bulk concentration of $\mathrm{OH}^{-}$. Approximate values for $\delta$ may be calculated using $\delta=\sqrt{ }(2 D t)$, where $t$ is the time over which the reaction proceeds. For a $\mathrm{CV}$ analysis carried out at $10 \mathrm{mV}$ $\mathrm{s}^{-1}$ (such as in Figure 4), $t$ is of the order of $10 \mathrm{~s}$, resulting in $\delta$ of $0.03 \mathrm{~cm}$. For the in situ XAS and IR experiments shown in Figures 3 and $5, t$ is greater than $100 \mathrm{~s}$, resulting in $\delta$ of $0.1 \mathrm{~cm}$ and above. Substituting these values into eq 6 , along with $j$ of approximately $1 \mathrm{~mA} \mathrm{~cm}^{-2}$ (from Figure 4), $D$ from the literature ${ }^{36}$ of $5 \times 10^{-5} \mathrm{~cm}^{2} \mathrm{~s}^{-1}$, and $\left[\mathrm{OH}^{-}\right]_{\mathrm{x}}=\delta$ of $1 \times 10^{-10}$ mol cm $\mathrm{cm}^{-3}$ (bulk solution of approximately $\mathrm{pH} 7$ ), results in values of $\left[\mathrm{OH}^{-}\right]_{x=0}$ of $1 \times 10^{-3} \mathrm{~mol} \mathrm{~cm}^{-3}$ during a typical CV analysis and $1 \times 10^{-2} \mathrm{~mol} \mathrm{~cm}^{-3}$ for in situ XAS and IR experiments. These concentrations correspond to interfacial $\mathrm{pH}$ values of 11 and 12, respectively. The HendersonHasselbalch equation can be used to calculate the anticipated increase in $\mathrm{PO}_{4}{ }^{3-}$ concentration associated with a $\mathrm{pH}$ of 12 , using the $\mathrm{p} K_{\mathrm{a}}$ value for eq 5. A concentration increase of 35 $\mathrm{mM}$ is predicted, which is consistent with the spectral changes observed at $-0.6 \mathrm{~V}$ in Figure 5. In previous studies, we have observed spectral changes of similar magnitude for concentration changes in this range, obtained through calibration. ${ }^{35}$ The spectral changes and this calculation support the proposal that water reduction increases interfacial $\mathrm{OH}^{-}$concentration sufficiently to promote the transformation of iron sulfides into hydroxides. The loss of the $\mathrm{PO}_{4}{ }^{3-}$ band over time indicates that the local $\mathrm{pH}$ drops after the initial increase, likely due to buffering. Similar local increases in $\mathrm{pH}$ (to $>12$ ) during electrochemical $\mathrm{H}_{2}$ evolution at $\mathrm{n}-\mathrm{GaAs}$ electrodes have also been observed using ATR IR spectroscopy. ${ }^{22}$

Nature of the Iron Hydroxide. In situ XANES spectra show that the hydroxide component of the electrode material persists and remains stable when potentials of $+0.2 \mathrm{~V}$ are subsequently applied and throughout a second cycle of negative applied potentials (Supporting Information, S3). This indicates that once formed, the hydroxide is not stripped off by electrochemical oxidation or reduction and is stable to electrochemical cycling. This enables us to assign the $\mathrm{O} 1$ and $\mathrm{O} 2$ peaks in the $\mathrm{CV}$ reverse scan (Figure 4) to redox processes associated with the hydroxide. One example of such a redox process is given in eq 7

$$
\begin{aligned}
& \mathrm{Fe}(\mathrm{II})_{2} \mathrm{Fe}(\mathrm{III})(\mathrm{OH})_{7}+\mathrm{OH}^{-} \\
& \quad \rightarrow \mathrm{Fe}(\mathrm{II}) \mathrm{Fe}(\mathrm{III})_{2}(\mathrm{OH})_{8}+\mathrm{e}^{-}
\end{aligned}
$$

However, it is not possible to definitively assign $\mathrm{O} 1$ or $\mathrm{O} 2$ to this reaction or one of the many different reported redox reactions for both iron oxides/hydroxides and solution sulfide species over this potential range. ${ }^{15-20}$ This is due to the uncertain and amorphous nature of the iron hydroxide and a lack of clarity in the literature regarding redox potentials of potential sulphide and sulphoxide species that could be present. Similarly, peaks R2 and R3 on subsequent scans are attributed to the reverse of eq 7 and similar reactions.

The XANES data showing a final greigite content of $60 \%$ with $\mathrm{Fe}$ hydroxides contributing $40 \%$ could be interpreted in two ways. The first interpretation is that $40 \%$ of the greigite nanoparticles are entirely converted to hydroxide, with the remaining $60 \%$ completely unchanged. This could be the case if some greigite particles are not in close contact with the solution (e.g., embedded within the carbon support matrix) and hence do not respond to the solution $\mathrm{pH}$ change. The second interpretation is the formation of a sulfide-hydroxide core-shell structure during electrochemical reduction, where the surface layers of the majority of the greigite nanoparticles are transformed to hydroxide. The presence of a core-shell material is confirmed by HRTEM imaging of a greigite nanoparticle after $60 \mathrm{~min}$ of repeated cycling between -0.05 and $-0.80 \mathrm{~V}$ (Figure 6). A crystalline $\mathrm{Fe}_{3} \mathrm{~S}_{4}$ core can be seen,

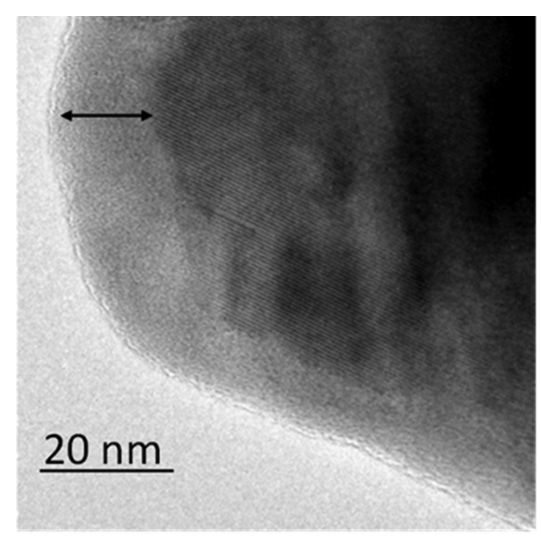

Figure 6. HRTEM image of a typical greigite nanoparticle after electrochemical cycling, where the black arrow indicates the amorphous shell.

surrounded by an amorphous layer of thickness $10-20 \mathrm{~nm}$. This can be compared to a HRTEM image of the assynthesized greigite, where the lattice pattern for the crystalline greigite can be seen to extend to the edge of the particle (Supporting Information, S1). Elemental line map analysis using energy dispersive X-ray (EDX) spectroscopy across the nanoparticle shows a high relative concentration of oxygen at the edge of the nanoparticle (Supplementary Information, S7). $\mathrm{XRD}$ analysis of the cycled particles shows only the presence of greigite, indicating that the shell structure is amorphous in nature and the greigite core remains intact (Supplementary Information, S8). The inability of XRD to pick up on the substantial chemical and structural changes to the surface of the greigite is an important observation, as XRD has often been used as a primary characterization method for these materials before and after use as a catalyst. Therefore, in previous work, there may have been changes to the catalyst surface that were undetected and hence unreported.

Computer modeling confirms that the incorporation of oxygen into the $\{111\}$ surface of greigite, simulated as replacement of one sulfur (forming $\mathrm{S}_{8}$ ) by one oxygen atom (from the $\mathrm{O}_{2}$ gas-phase molecule), is more favorable by 0.69 $\mathrm{eV}$ than the same reaction within the bulk conventional cubic unit cell of $\mathrm{Fe}_{3} \mathrm{~S}_{4}$. Oxygen incorporation into the $\{100\}$ surface is also thermodynamically preferred over the process in the bulk, but it is unfavorable by $0.23 \mathrm{eV}$ with respect to the $\{111\}$ plane. In addition, models of early oxidation stages of greigite have shown that basic aqueous conditions allow for substitution of sulfur by oxygen on the $\mathrm{Fe}_{3} \mathrm{~S}_{4}\{100\}$ surface but oxygen coordination is confined to the immediate subsurface layer and does not continue into the bulk. ${ }^{37}$ Thus, these models support the proposal that a core-shell structure is preferred over complete conversion to hydroxide. 
However, it should be noted that the experimental data do not preclude a mixed population of core-shell, 100\% greigite and $100 \%$ hydroxide nanoparticles. It is, however, clear from XANES spectra recorded over a second cycle of negative applied potential (Supporting Information, S3) that the proportion of greigite to hydroxide remains constant. This indicates that a shell of constant thickness is formed during the first hour of negative applied potential but does not continue to grow in thickness. The CV curve in Figure 4 shows that the peaks for the redox processes of the hydroxide increase in magnitude between the first and second scans, suggesting that the hydroxide layer is still growing on the timescale of the CV; however, after cycling for up to an hour, the peak magnitudes become constant, supporting the conclusions from the XANES data that the hydroxide layer does not grow indefinitely.

Influence of Dissolved $\mathrm{CO}_{2}$ on the Changes To Greigite at Negative Potential. As this same greigite material has previously been employed for electrochemical $\mathrm{CO}_{2}$ reduction using applied potentials over a similar range, ${ }^{24}$ it was of interest to determine changes to the greigite surface when dissolved $\mathrm{CO}_{2}$ is present in the solution. $\mathrm{CV}$ studies were repeated in $\mathrm{CO}_{2}$-saturated $\mathrm{pH} 6.8$ phosphate electrolyte (final $\mathrm{pH}=6.5)$. The positions of the $\mathrm{CV}$ peaks in $\mathrm{CO}_{2}$-saturated solution are the same as those in Figure 4, although the current magnitudes are 3 orders of magnitude lower (Supporting Information, S9). As the current magnitudes in the presence of $\mathrm{CO}_{2}$ are significantly smaller, this suggests that reduction of water and the resulting hydroxide redox chemistry are greatly suppressed in $\mathrm{CO}_{2}$-saturated solutions. At $\mathrm{pH} 6.5$, the major product of $\mathrm{CO}_{2}$ dissolution is $\mathrm{HCO}_{3}{ }^{-}$, which with a calculated binding energy of $-1.64 \mathrm{eV}$ is predicted to adsorb strongly to the $\{111\}$ face of the greigite nanoparticles (Table 1). ${ }^{24}$ In

Table 1. Calculated Binding Energies (BE) for the Electrolyte Species at the Greigite $\{100\}$ and $\{111\}$ Faces

\begin{tabular}{lcc} 
& $\mathrm{BE}$ at $\mathrm{Fe}_{3} \mathrm{~S}_{4}\{100\} / \mathrm{eV}$ & $\mathrm{BE}$ at $\mathrm{Fe}_{3} \mathrm{~S}_{4}\{111\} / \mathrm{eV}$ \\
{$\left[\mathrm{H}_{2} \mathrm{O}\right]_{10}$} & -0.66 & -0.73 \\
$\mathrm{HCO}_{3}{ }^{-}+\mathrm{H}^{+}$ & -0.30 & -1.64 \\
$\mathrm{CO}_{3}{ }^{2-}+2 \mathrm{H}^{+}$ & +1.24 & -0.46 \\
$\mathrm{H}_{2} \mathrm{PO}_{4}^{-}+\mathrm{H}^{+}$ & -1.00 & -0.33 \\
$\mathrm{HPO}_{4}{ }^{2-}+2 \mathrm{H}^{+}$ & -0.45 & +0.03 \\
\hline
\end{tabular}

contrast, $\mathrm{HCO}_{3}{ }^{-}$is not expected to bind competitively at the $\{100\}$ surface, as water, $\mathrm{H}_{2} \mathrm{PO}_{4}^{-}$, and $\mathrm{HPO}_{4}{ }^{2-}$ all have more negative binding energies. Therefore, the $\mathrm{CV}$ current magnitudes may be greatly decreased in the presence of $\mathrm{CO}_{2}$ because of the predicted passivation of the greigite $\{111\}$ face by a layer of adsorbed $\mathrm{HCO}_{3}{ }^{-}$, which could inhibit the water reduction reaction from taking place at this surface, as well as protecting the surface from reaction with generated hydroxide. Subsequent formation of the hydroxide shell is therefore suppressed and the lack of resulting redox processes (e.g. eq 7) leads to lower currents. The inhibition of the formation of the hydroxide is confirmed by in situ XANES spectra obtained at $-0.60 \mathrm{~V}$ in $\mathrm{CO}_{2}$-saturated solution (Supporting Information, $\mathrm{S} 10)$. The edge shoulder $\mathbf{B}$ is present in all spectra, showing that $\mathrm{Fe}-\mathrm{S}$ bonding is maintained and the white line intensity $\mathbf{C}$ barely increases. After $60 \mathrm{~min}$, LCF analysis shows that hydroxide contributes only $10 \%$ to the spectrum, compared to $40 \%$ when $\mathrm{CO}_{2}$ is not present. In situ IR spectroelectrochemistry in the $\mathrm{CO}_{2}$-saturated solution shows that the $\mathrm{PO}_{4}{ }^{3-}$ species is still generated in the solution at $-0.60 \mathrm{~V}$ (Supporting
Information, $\mathrm{S} 11$ ), indicating that the increase in interfacial $\mathrm{pH}$ to $>11$ still takes place, but the resulting change in surface chemistry is suppressed. These results show that the greigite surface remains relatively stable under conditions of $\mathrm{CO}_{2}$ reduction, although slow transformation to the hydroxide may take place over time.

\section{CONCLUSIONS}

In situ XANES spectroscopy has revealed that at $-0.6 \mathrm{~V}$ versus SHE in a pH 7 electrolyte, a greigite electrode loses sulfur, which is replaced by oxygen, resulting in a $60 \%$ greigite $40 \% \mathrm{Fe}$ hydroxide product. The resulting hydroxide that is formed is amorphous and stable to potential cycling. In $\mathrm{CO}_{2}$-saturated solution, the formation of the hydroxide is inhibited. HRTEM along with computational calculations suggest a greigitehydroxide core-shell structure for the product. This transformation is proposed to take place due to the large increase in local $\mathrm{pH}$ at the electrode caused by the HER taking place at this potential. An increase in $\mathrm{pH}$ to 12 was confirmed using in situ IR spectroscopy to monitor changes in the solution phosphate species at the electrode interface. These results, therefore, show that the true nature of a greigite electrocatalyst under conditions of the HER is a greigite-hydroxide core-shell material. This study suggests that sulfide materials that have been proposed as HER electrocatalysts should be similarly examined under operating conditions. However, ex situ characterization techniques such as XRD may not detect the presence of amorphous oxide materials, especially if confined to the surface of the catalyst. For this reason, in situ studies using techniques such as XAS can provide better information about the real surface structure and chemistry, which are essential when developing mechanistic models. However, a simple consideration of possible changes to the catalyst that could be induced by changes in surface $\mathrm{pH}$ may provide researchers with an insight into catalyst stability and function in the HER.

\section{ASSOCIATED CONTENT}

\section{Supporting Information}

The Supporting Information is available free of charge on the ACS Publications website at DOI: 10.1021/acsami.8b08612.

Greigite synthesis and characterization; HRTEM image of as-synthesized greigite; in situ XANES experiments; LCF analysis of XANES and EXAFS analysis; ex situ $S$ K-edge XANES; in situ IR spectroelectrochemistry experiment and computational methods; HRTEM, EDX, and XRD analysis of greigite after cycling; and cyclic voltammogram, XANES spectra, EXAFS analysis, and in situ IR spectra of greigite in the $\mathrm{CO}_{2}$-saturated solution (PDF)

\section{AUTHOR INFORMATION}

\section{Corresponding Authors}

*E-mail: k.b.holt@ucl.ac.uk (K.B.H.).

*E-mail: DeLeeuwN@cardiff.ac.uk (N.H.d.L.).

ORCID

David Santos-Carballal: 0000-0002-3199-9588

Wim Bras: 0000-0001-5070-4039

Gopinathan Sankar: 0000-0001-5152-3424

Katherine B. Holt: 0000-0002-3644-1663

Nora H. de Leeuw: 0000-0002-8271-0545 


\section{Notes}

The authors declare no competing financial interest.

\section{ACKNOWLEDGMENTS}

UK Engineering and Physical Sciences Research Council (EPSRC) grants EP/H046313, EP/K035355/1 and EP/ K035355/2; Ramsay Memorial Trust Fellowship (A.R.); UCL Industrial Doctorate Centre for Molecular Modelling and Materials Science (ESPRC grant EP/G036675) and Dutch-Belgian Beamline at ESRF (DUBBLE) studentship (HUI); Royal Society Industry Fellowship (NHdL); Universiti Brunei Darussalam Chancellor's scholarship (SNAZ). We have used HECToR and ARCHER via membership of the UK's HPC Materials Chemistry Consortium (grants EP/L000202 and EP/F067496), UCL Legion High Performance Computing (Legion@UCL), Advanced Research Computing@Cardiff (ARCCA) Division, Cardiff University and HPC Wales.

\section{REFERENCES}

(1) Zhang, Y.; Zhou, Q.; Zhu, J.; Yan, Q.; Dou, S. X.; Sun, W. Nanostructured Metal Chalcogenides for Energy Storage and Electrocatalysis. Adv. Funct. Mater. 2017, 27, 1702317.

(2) Gao, M.-R.; Zheng, Y.-R.; Jiang, J.; Yu, S.-H. Pyrite-Type Nanomaterials for Advanced Electrocatalysis. Acc. Chem. Res. 2017, 50, 2194-2204.

(3) Anantharaj, S.; Ede, S. R.; Sakthikumar, K.; Karthick, K.; Mishra, S.; Kundu, S. Recent Trends and Perspectives in Electrochemical Water Splitting with an Emphasis on Sulfide, Selenide, and Phosphide Catalysts of $\mathrm{Fe}, \mathrm{Co}$, and Ni: A Review. ACS Catal. 2016, 6, 80698097.

(4) Jaramillo, T. F.; Jorgensen, K. P.; Bonde, J.; Nielsen, J. H.; Horch, S.; Chorkendorff, I. Identification of Active Edge Sites for Electrochemical H2 Evolution from MoS2 Nanocatalysts. Science 2007, 317, 100-102.

(5) Vrubel, H.; Merki, D.; Hu, X. Hydrogen evolution catalyzed by MoS3 and MoS2 particles. Energy Environ. Sci. 2012, 5, 6136-6144.

(6) Çimen, Y.; Peters, A. W.; Avila, J. R.; Hoffeditz, W. L.; Goswami, S.; Farha, O. K.; Hupp, J. T. Atomic Layer Deposition of Ultrathin Nickel Sulfide Films and Preliminary Assessment of Their Performance as Hydrogen Evolution Catalysts. Langmuir 2016, 32, 1200512012.

(7) Sun, Y.; Liu, C.; Grauer, D. C.; Yano, J.; Long, J. R.; Yang, P.; Chang, C. J. Electrodeposited Cobalt-Sulfide Catalyst for Electrochemical and Photoelectrochemical Hydrogen Generation from Water. J. Am. Chem. Soc. 2013, 135, 17699-17702.

(8) Villalba, M.; Peron, J.; Giraud, M.; Tard, C. pH-Dependence on HER Electrocatalytic Activity of Iron Sulfide Pyrite Nanoparticles. Electrochem. Commun. 2018, 91, 10-14.

(9) Jasion, D.; Barforoush, J. M.; Qiao, Q.; Zhu, Y.; Ren, S.; Leonard, K. C. Low-Dimensional Hyperthin FeS2 Nanostructures for Efficient and Stable Hydrogen Evolution Electrocatalysis. ACS Catal. 2015, 5, 6653-6657.

(10) Miao, R.; Dutta, B.; Sahoo, S.; He, J.; Zhong, W.; Cetegen, S. A.; Jiang, T.; Alpay, S. P.; Suib, S. L. Mesoporous Iron Sulfide for Highly Efficient Electrocatalytic Hydrogen Evolution. J. Am. Chem. Soc. 2017, 139, 13604-13607.

(11) Faber, M. S.; Lukowski, M. A.; Ding, Q.; Kaiser, N. S.; Jin, S. Earth-Abundant Metal Pyrites (FeS2, CoS2, NiS2, and Their Alloys) for Highly Efficient Hydrogen Evolution and Polysulfide Reduction Electrocatalysis. J. Phys. Chem. C 2014, 118, 21347-21356.

(12) Di Giovanni, C.; Wang, W.-A.; Nowak, S.; Grenèche, J.-M.; Lecoq, H.; Mouton, L.; Giraud, M.; Tard, C. Bioinspired Iron Sulfide Nanoparticles for Cheap and Long-Lived Electrocatalytic Molecular Hydrogen Evolution in Neutral Water. ACS Catal. 2014, 4, 681-687.

(13) Di Giovanni, C.; Reyes-Carmona, Á.; Coursier, A.; Nowak, S.; Grenèche, J. M.; Lecoq, H.; Mouton, L.; Rozière, J.; Jones, D.; Peron, J.; Giraud, M.; Tard, C. Low-Cost Nanostructured Iron Sulfide
Electrocatalysts for PEM Water Electrolysis. ACS Catal. 2016, 6, 2626-2631.

(14) Rickard, D.; Luther, G. W. Chemistry of Iron Sulfides. Chem. Rev. 2007, 107, 514-562.

(15) Conway, B. E.; Ku, J. C. H.; Ho, F. C. The electrochemical surface reactivity of iron sulfide, FeS2. J. Colloid Interface Sci. 1980, 75, $357-372$.

(16) Mycroft, J. R.; Bancroft, G. M.; Mcintyre, N. S.; Lorimer, J. W.; Hill, I. R. Detection of Sulphur and Polysulphides on Electrochemically Oxidized Pyrite Surfaces by X-Ray Photoelectron Spectroscopy and Raman Spectroscopy. J. Electroanal. Chem. 1990, 292, 139-152.

(17) Tao, D. P.; Richardson, P. E.; Luttrell, G. H.; Yoon, R.-H. Electrochemical Studies of Pyrite Oxidation and Reduction Using Freshly-Fractured Electrodes and Rotating Ring-Disc Electrodes. Electrochim. Acta 2003, 48, 3615-3623.

(18) Hamilton, I. C.; Woods, R. An Investigation of Surface Oxidation of Pyrite and Pyrrhotite by Linear Potential Sweep Voltammetry. J. Electroanal. Chem. 1981, 118, 327-343.

(19) Mikhlin, Y. Reactivity of Pyrrhotite Surfaces: An Electrochemical Study. Phys. Chem. Chem. Phys. 2000, 2, 5672-5677.

(20) Bura-Nakic, E.; Róka, A.; Ciglenecki, I.; Inzelt, G. Electrochemical Quartz Crystal Microbalance Study of FeS Particles Attached to Au Surface. Electroanalysis 2009, 21, 1699-1708.

(21) Anderko, A.; Shuler, P. J. A Computational Approach to Predicting the Formation of Iron Sulfide Species Using Stability Diagrams. Comput. Geosci. 1997, 23, 647-658.

(22) Erné, B. H.; Maroun, F.; Ozanam, F.; Chazalviel, J.-N. Local pH Change during Diffusion-Limited Proton Reduction Determined by In Situ Infrared Spectroscopy. Electrochem. Solid-State Lett. 1999, 2, 231-232.

(23) Ning, J.; Zheng, Y.; Brown, B.; Young, D.; Nešić, S. A Thermodynamic Model for the Prediction of Mild Steel Corrosion Products in an Aqueous Hydrogen Sulfide Environment. Corrosion 2015, 71, 945-960.

(24) Roldan, A.; Hollingsworth, N.; Roffey, A.; Islam, H.-U.; Goodall, J. B. M.; Catlow, C. R. A.; Darr, J. A.; Bras, W.; Sankar, G.; Holt, K. B.; Hogarth, G.; de Leeuw, N. H. Bio-inspired CO2 conversion by iron sulfide catalysts under sustainable conditions. Chem. Commun. 2015, 51, 7501-7504.

(25) Vladimirov, M. G.; Ryzhkov, Y. F.; Alekseev, V. A.; Bogdanovskaya, V. A.; Otroshchenko, V. A.; Kritsky, M. S. Electrochemical Reduction of Carbon Dioxide on Pyrite as a Pathway for Abiogenic Formation of Organic Molecules. Origins Life Evol. Biospheres 2004, 34, 347-360.

(26) Yamaguchi, A.; Yamamoto, M.; Takai, K.; Ishii, T.; Hashimoto, K.; Nakamura, R. Electrochemical CO 2 Reduction by Ni-containing Iron Sulfides: How Is CO 2 Electrochemically Reduced at BisulfideBearing Deep-sea Hydrothermal Precipitates? Electrochim. Acta 2014, 141, 311-318.

(27) Yuhas, B. D.; Prasittichai, C.; Hupp, J. T.; Kanatzidis, M. G. Enhanced Electrocatalytic Reduction of CO2with Ternary NiFe4S4and Co-Fe4S4-Based Biomimetic Chalcogels. J. Am. Chem. Soc. 2011, 133, 15854-15857.

(28) Mikhlin, Y.; Tomashevich, Y.; Vorobyev, S.; Saikova, S.; Romanchenko, A.; Félix, R. Hard X-Ray Photoelectron and X-Ray Absorption Spectroscopy Characterization of Oxidized Surfaces of Iron Sulfides. Appl. Surf. Sci. 2016, 387, 796-804.

(29) Womes, M.; Karnatak, R. C.; Esteva, J. M.; Lefebvre, I.; Allan, G.; Olivier-Fourcade, J.; Jumas, J. C. Electronic Structures of FeS and $\mathrm{FeS}_{2}$ : X-Ray Absorption Spectroscopy and Band Structure Calculations. J. Phys. Chem. Solids 1997, 58, 345-352.

(30) Sugiura, C. Iron K x-ray absorption-edge structures of $\mathrm{FeS}$ and FeS2. J. Chem. Phys. 1984, 80, 1047-1049.

(31) de Groot, F.; Vankó, G.; Glatzel, P. The 1s X-Ray Absorption Pre-Edge Structures in Transition Metal Oxides. J. Phys.: Condens. Matter 2009, 21, 104207.

(32) Colpas, G. J.; Maroney, M. J.; Bagyinka, C.; Kumar, M.; Willis, W. S.; Suib, S. L.; Mascharak, P. K.; Baidya, N. X-Ray Spectroscopic 
Studies of Nickel Complexes, with Application to the Structure of Nickel Sites in Hydrogenases. Inorg. Chem. 1991, 30, 920-928.

(33) Wilke, M.; Farges, F.; Petit, P.-E.; Brown, G. E.; Martin, F. Oxidation state and coordination of Fe in minerals: An FeK-XANES spectroscopic study. Am. Mineral. 2001, 86, 714-730.

(34) Arai, Y.; Sparks, D. L. ATR-FTIR Spectroscopic Investigation on Phosphate Adsorption Mechanisms at the Ferrihydrite-Water Interface. J. Colloid Interface Sci. 2001, 241, 317-326.

(35) Lounasvuori, M. M.; Holt, K. B. Acid Deprotonation Driven by Cation Migration at Biased Graphene Nanoflake Electrodes. Chem. Commun. 2017, 53, 2351-2354.

(36) Lee, S. H.; Rasaiah, J. C. Proton transfer and the mobilities of the $\mathrm{H}+$ and $\mathrm{OH}-$ ions from studies of a dissociating model for water. J. Chem. Phys. 2011, 135, 124505.

(37) Santos-Carballal, D.; Roldan, A.; de Leeuw, N. H. Early Oxidation Processes on the Greigite Fe3S4(001) Surface by Water: A Density Functional Theory Study. J. Phys. Chem. C 2016, 120, 86168629. 